\title{
HOW SAFE IS YOUR SMART CITY?
}

Jozsef Papp*

Óbuda University, Kálmán Kandó Faculty of Electricity

Budapest, Hungary

DOI: $10.7906 /$ indecs.20.1.8

Regular article

Received: 3 April 2020.

Accepted: 31 December 2021.

\section{ABSTRACT}

As far as I am concerned, not at all, and I am going to show why! When most people hear the expression 'Smart City', they associate it with a future city where thousands of sensors are installed and connected with each other and the central computer-based unit. Other groups of people think of the smart city as represented by high quality and future visionary high-end instruments and electric cars. However, the smart city is based on an interaction between city systems, public safety, health, education, and citizens' services. This cooperation makes the city a healthier, safer place for people to live in. Nowadays, public safety is of paramount importance like energy management, smart transport, or building automation. In this article, I am going to describe how we can manage public safety by transforming the city environment in a proprietary way. I use the principles of Crime Prevention Through Environmental Design for redesigning the city environment.

\section{KEY WORDS}

smart city, CPTED, crime prevention, public safety, smart systems

\section{CLASSIFICATION}

ACM: 10003752.10010070

JEL: O39 


\section{INTRODUCTION}

The global population is currently more than 7 billion and is predicted to top out around 10 billion. Today, more than half of all people in the world live in an urban area. By mid-century, $70 \%$ of the world's population will be living in cities covering less than $2 \%$ of the Earth's surface $[1,2]$. The challenges of cities are changing rapidly. This raises many issues: pollution, infrastructure access, traffic congestion, mobility, safety, clean drinking water, waste management and the health of residents are only a few examples. The massive population is overburdening services. Poverty and crime are still far too high. In many cases, cities concentrate too many people on small areas and the overpopulation results in a high degree of indifference, impersonality and isolation. The focus of transforming the urban environment should be on the individual, the community and the environment [3]. How can we handle this high degree of urbanization and how does it affect our future?

\section{A SMART CITY}

The development of the built area and combination of new technologies such as the Internet of Things and Artificial Intelligence offer a multifaceted solution: the smart city or intelligent city. The Internet of Things allows you to analyze your environment and make real-time adjustments to improve productivity and efficiency. This efficiency can be felt throughout the city from a more efficient power grid to optimized traffic and seamless connectivity [4, 5].

Based on these we can create the definition of the smart city: Smart cities are safe, green and hyper-connected cities, technologically equipped to improve the lives of their residents. "The purpose of an intelligent city or Smart City is to create a standardised, cooperative structure by the integration of subsystems" [6].

At this point, an important question arises: "what is the difference between an intelligent city and a smart city?" A lot of people think these two terms are synonyms. They differ according to me. Here is my definition of these concepts [7]:

- "the primary objective of the intelligent city is to promote the integration of various subsystems in order to be able to cooperate with each other in a coherent way. "The different types and different functions of these subsystems help each other, which affects the operation of the entire infrastructure" [6].

- "Smart city is an intelligent city in which services can be exploited by users in a maximal way"[8].

"Smart City should enable every citizen to engage with all the services on offer, public as well as private, in a way which best suits his or her needs. It brings together hard infrastructure, social capital including local skills and community institutions, and (digital) technologies to fuel sustainable economic development and provide an attractive environment for all'"[7].

"The principle of subsidiarity may be applied at the introduction of a new intelligent system. According to this principle, problems must be solved where they emerge, so higher-level intervention is only necessary if the problem cannot be solved on its level and it would interfere with the operation of the entire network"[8]. "The use of the word 'ambient' refers to the fact that the architecture that this technology utilizes allows the devices to continually monitor their own systems and the systems surrounding them with the help of sensors and measurements at a local level - where it is needed. Certain authorized elements may also intervene in operating mechanisms. At the same time they are also able to inform the elements in higher 'evolutionary' positions, and if necessary, send them warnings or alerts. 
Each element of the system operates autonomously, but they work in dynamic cooperation. For example, sensors of the system can work this way"[8].

As the population grows and traffic jams get more common, some cities end up with a higher crime rate. This affects everyone: business owners, tourism and, of course, families. Big changes often require a comprehensive look. In this article, I am going to take a broad approach describing how to provide the citizens with a lasting sense of security. Instead of just responding to occasional demands, stakeholders came up with a long-term plan. Big changes do not happen overnight. While cities continuing to grow and citizens' expectations increasing, we shall reconsider how cities are built and run. According to my research, a Smart City must have decentralized systems with shared logic. These systems provide real-time data, relying on which the law enforcement officials are informed on ongoing events straight away as they take place. Hot information enables the dedicated body to take preventive measures before the damage becomes extensive [9].

\section{LIVABLE CITY}

Why is the city so attractive? Because the City is the highest level of organization form of human settlement. The physical and functional factors that meet the individual needs the most effective way are concentrated here.

What makes a city fine? Perhaps, the best answer to this is that the people who live there feel that way and they are willing to make sacrifices for it. But this concept requires more than doing modernization or 'getting smart'. We have to make the city livable. The city is for people who live there, its task is to serve the inhabitants as much as possible. All initiatives must be subordinated to this principle.

What makes a city livable? In a livable city, the residents feel good and safe. The basis of our existence is safety, without this, we cannot imagine a well-functioning community. All the residents, and communities - e.g. family, street, district - have a basic need to feel safe in the physical space around them which is called a built environment. This safety is provided by the absence of fear of crime, clean and tidy neighbourhoods, transparent parks, illuminated recreational spaces, clear traffic signals and predictable and reliable transport. With all these, the city can create communities in which people can take responsibility for their environment and their neighbourhood. This can form the basis of a higher standard of living and a more structured society [10].

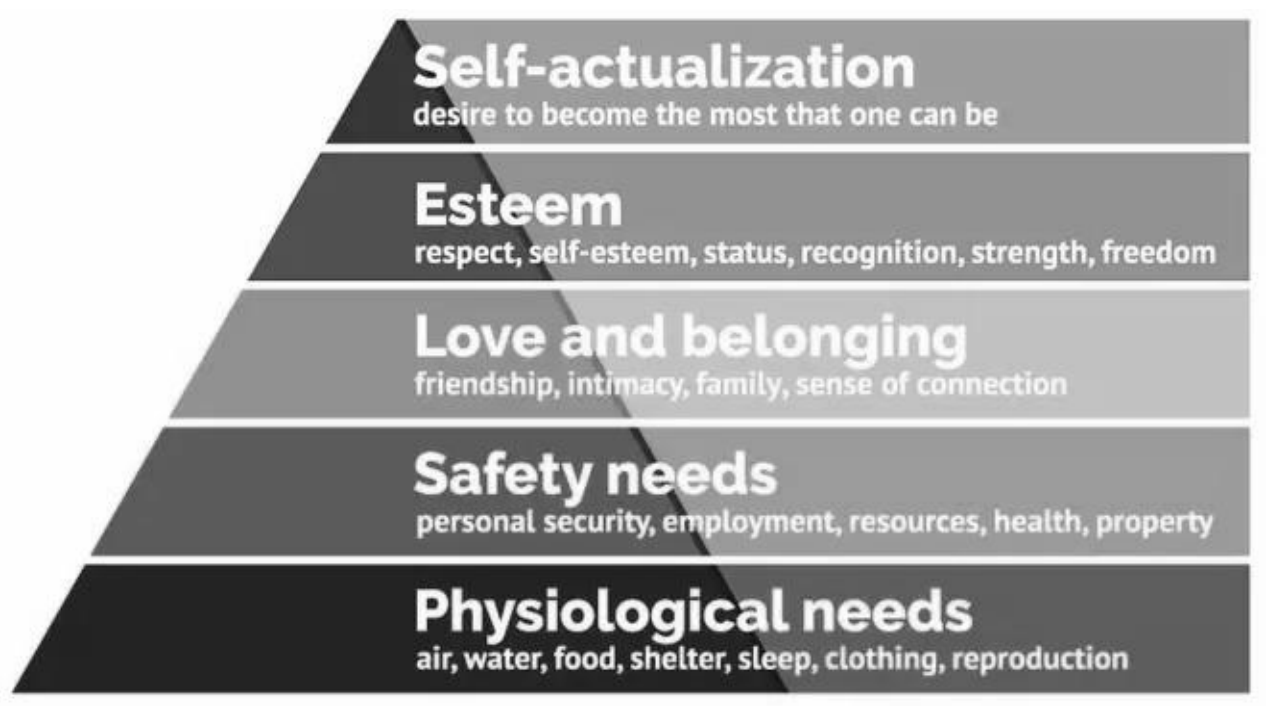

Figure 1. Maslow's hierarchy of needs [11]. 
Safety is one of the most essential motivation factors for humans, located in the second level of Maslow's hierarchy of needs stated that people are motivated to achieve certain needs and that some needs take precedence over others.). When we talk about Smart City, we mean a city which not only helps peoples' everyday lives with the design of technological, IT and environmental equipment. It is also a place where public spaces, parks, homes, buildings, streets or neighbourhoods are designed to provide the maximum safety for the residents using a demonstration of quantitative and qualitative changes in crime. Needless to say, technology will play a central role. Urban and rural areas are evolving to cater to changes in technology while presenting new opportunities for improved Public Safety. Connectivity and the overall experience for residents and visitors, city officials are specifically tasked with the challenge of providing safe and secure settings, network connectivity, reliable and sustainable power, modern living and working conditions and ultimately a seamless and data-driven operating environment. Creating a safe, secure city requires preparing for a wide variety of challenges from protecting critical infrastructure to mitigating the risks of terrorism and cyber-attacks. Deploying a 24/7 crime prevention and Public Safety strategy is essential to proactively maintain safety while also allowing emergency professionals to respond quickly in a crisis situation. According to many academic sources and, in addition, to my own experience, I have developed the following definition of Liveable City. A Livable City is a level of urbanization that uses smart city's innovative technology to enhance community services as well as it uses Environmentally Sensitive Crime Prevention to increase the safety feeling of the residents. These two parts of the design process create economic opportunities that improve the city infrastructure, reduce costs (maintenance costs) and resource consumption and increases civic engagement. Let me take a few moments to discuss the potential highlevel planning steps for developing a Smart City. A smart city is not a single or small collection of projects. Ideally, a smart city begins with a vision $[12,13]$. It's essential as a first step because it will guide every decision that comes next. The truth is that, when you have a long-term vision, big changes can happen right before your eyes.

\section{HOW CAN WE DESIGN A SAFER SMART CITY}

The answer ... is not just one thing. No single solution can fix everything. We need connected systems and collaborating teams, greater intelligence to discover the unseen [14].

The focus of transforming the urban environment should be on the citizens, the community and the environment. We can meet this requirement if the redesign of the neighbourhoods or built-up areas serve the needs of the city dwellers. One of these demands - even if many people are not aware of this - is the emergence of human communities. The careful urban planning that focuses on safety and livelihoods should strive to divide the built environment into smaller units, despite the large masses of people, where the chances of human observant communities remain.

Our built environment is the space in which we are continuously interacting. Our communication is often unnoticeable. When we walk down the street, sit down in a park, come to a plaza or park our car, we perceive the environment at all moments from which conscious and unconscious conclusions are drawn. It is important that we grab all the tools which can form the environment (rather than the individual's permanent but constantly changing framework) in a way that it provides us with a sense of security at all times. The presence or lack of a subjective sense of security is fundamental to our behaviour and attitudes towards other members of society, our environment and our living space. I use the principles of Crime Prevention Through Environmental Design (CPTED) for redesigning the city environment. These are 'natural surveillance', 'access control', 'territoriality', 'activity support' and 'management and maintenance'. These principles are based on continuous monitoring of the number of crimes and other economic and social data. Measuring data is 
very important for us. It helps to make decisions in good shape. It is very important to the government, mostly for security related issues.

What is CPTED? It is defined as a "multi-disciplinary approach for reducing crime through urban and environmental design and the management and use of built environments. CPTED strategies aim to reduce victimization, deter offender decisions that precede criminal acts, and build a sense of community among inhabitants so they can gain territorial control of areas and reduce opportunities for crime and fear of crime" [15]. Its directives include adjusting the height and quality of fences, improving public lighting, maintenance of streets and buildings, controlling and damping traffic, providing people with information about their environment, marking boundaries of land and private and public spaces, use of security systems, and development of natural oversight and community control.

The basic concept is to create a built environment which includes spaces, streets, and residential parks that are less liable to invite committing crimes. Where we experience clean, bright, transparent spaces, tidy, maintained parks and other community service areas. There is a need for zones, districts, and neighbourhoods where functions and people mingle, thus avoiding sleeping quarters. The goal is to control urbanization and to keep the human dimension in mind.

In order to live in our environment, and in our built environment in particular, which provides us adequate living space and quality, many other factors affecting the environment must be reconsidered. These include colours, space shapes, illumination, and proper usage of vegetation. It may not be sufficient to state that the community can do its best to prevent crime, but it must be facilitated by creating the right environment to enhance the community's natural need to protect it in the first place [15-17].

\section{INTERVENTIONS POINT}

Crime and harm are the most common human activities which are often discovered through human intervention. The current highly centralized and human-based smart city systems are not capable of signalling emerging disaster situations early due to their reliability. As a result, response can only be given with a lag.

When applying environmentally sensitive crime prevention, nine intervention points are identified. These points help to determine the applicability of the principles and the methods that mutually support each other. Since we cannot find two identical areas or problems, the solutions given to them are not uniform. It is more important to have a set of criteria which we can start applying. Let's review these intervention points [10]:

1. Mix of people: in this intervention point we are going to design or redesign city areas whose role is to build social relationships, e.g. pedestrian streets, public spaces, etc.

2. Mix of functions: it is very important for an area to be alive as much of the time as possible. It is therefore necessary to combine functions such as trade and culture or other services and non-industrial workspaces such as large shopping malls.

3. Social control: as we have seen, the role of the community in crime preventionis much greater than we would expect. There is a major need to strengthen social cohesion and develop community functions.

4. Define space: as I stated earlier, environmentally sensitive crime prevention only works if it is focused on a well-defined area. The task is to increase community control by subdividing the area into the appropriate 'size'.

5. Lighting: for community control to function properly, the 'protected area' must be made visible and this can only be done with artificial lighting at certain times of the day. 
6. Protection: we are not able to implement community control at every point of the area, so we need to optimise (centralise) surveillance, deter 'intruders' or make it difficult for them to operate.

7. Management: the built environment, even a relatively durable construction is constantly decaying and being worn out. If we do not maintain it from time to time, it will create negative effects that are more difficult to eliminate. For example: "One unrepaired broken window is a signal that no one cares, and so breaking more windows costs nothing" [18]. This is the broken window theory. "The broken windows theory states that visible signs of disorder and misbehavior in an environment encourage further disorder and misbehavior, leading to serious crimes. The principle was developed to explain the decay of neighborhoods, but it is often applied to work and educational environments" [18].

8. Information: it is essential that a person feels uncomfortable and depressed in an area which they are unfamiliar with. It is important to inform and to help citizens to navigate in the built environment.

9. Urban design: Prevention is more effective than 'rubble clearance', so if it is possible, we have to prepare the citizens for the right usage of the area.

\section{CONCLUSIONS}

I have argued in this that those smart cities which did not focus on environmentally sensitive crime prevention are not safe enough. The prophylaxis requires a complex approach in which setting priorities is important but pluralism in the methods is just as essential. The future will focus most likely on cities where, depending on the urban citizens, the population and crime rate will continue to increase. Urban design must put much more emphasis on the principles of environmentally sensitive crime prevention.

\section{REFERENCES}

[1] World Health Organization: Global Health Observatory. Urban Health, 2013,

[2] United Nations: World Urbanization Prospects.

The 2011 Revision, New York, 2012,

[3] Manville, C., et al.: Mapping Smart Cities in Europe Direcorate General for Internal Policies.

http://www.europarl.europa.eu/RegData/etudes/etudes/join/2014/507480/IPOL-ITRE_ET(2014)5 07480_EN.pdf, accessed $16^{\text {th }}$ January 2019,

[4] Bizjan, B.: Smart cities in Europe an overview of existing projects and good practices. Smart Cities Conference, 2014,

[5] Harrison, C., et al.: Foundations for Smarter Cities.

IBM Journal of Research and Development 54(4), 1-16, 2010, http://dx.doi.org/10.1147/JRD.2010.2048257,

[6] Papp, J.: Embedded Control System with Shared Logic for Railroad Transport. Innorail Special Edition 2016 3(1), 40-41, 2016,

[7] Tokody, D.; Schuster, G. and Papp, J.: Smart City, Smart Infrastructure, Smart Railway. International Conference on Applied Internet and Information Technologies, University of Novi Sad, Zrenjanin, 2015,

[8] Tokodi, D.; Schuster, G. and Papp, J.: The challenges of the intelligent railway network implementation.

$3^{\text {rd }}$ international conference and workshop Mechatronics in Practice and Education - MECHEDU 2015. Subotica Technical College of Applied Sciences, Subotica, 2015,

[9] Papp, J.; Tokody, D. and Flammini, F.: From traditional manufacturing and automation systems to holonic intelligent systems.

Procedia Manufacturing 22, 931-935, 2018, http://dx.doi.org/10.1016/j.promfg.2018.03.132, 
[10]Barabás, A.T.; Dallos, E.; Molnár, I.J. and Papp, J.: Environmentally sensitive crime prevention in smart cities. In Hungarian.

Kriminológiai Tanulmányok 2000(56), 121-142, 2019, http://dx.doi.org/10.1002/phbl.20000560325,

[11] Mcleod, S.: Maslow's Hierarchy of Needs. http://www.simplypsychology.org/maslow.html, accessed $20^{\text {th }}$ January 2019,

[12] Smart Cities and Communities: Key Messages for the High-Level Group from the Smart Cities Stakeholder Platform Roadmap Group. http://www.yumpu.com/en/document/view/28452233/key-messages-to-the-high-level-group-sma rt-cities-,

[13] Anthopoulos, L. and Fitsilis, P.: From Digital to Ubiquitous Cities: Defining a Common Architecture for Urban Development.

Proceedings of the $6^{\text {th }}$ International Conference on Intelligent Environments, IEEE, Kuala Lumpur, 2010,

[14] Szczech, E.: Concept of "Smart City" and its Practice in Poland. Case Study of Łódź City. Proceedings of $19^{\text {th }}$ International Conference on Urban Planning, Regional Development and Information Society, pp.169-180, 2014,

[15] The International Crime Prevention Through Environmental Design Association:-. http://www.cpted.net, accessed $16^{\text {th }}$ January 2019 ,

[16] Silverman, E.B.: NYPD Battles Crime: Innovative Strategies in Policing. Northeastern University Press, Boston, 1999,

[17]Eck, E.J. and Maguire, E.R.: Have Changes in Policing Reduced Violent Crime? Cambridge University Press, Cambridge, 2006,

[18]Psychology Today Staff: Broken Windows Theory. http://www.psychologytoday.com/us/basics/broken-windows-theory, accessed $15^{\text {th }}$ January 2019. 